Article

\title{
Comparative Removal of Lead and Nickel Ions onto Nanofibrous Sheet of Activated Polyacrylonitrile in Batch Adsorption and Application of Conventional Kinetic and Isotherm Models
}

\author{
Muhammad Tahir Amin ${ }^{1,2, *(\mathbb{D})}$, Abdulrahman Ali Alazba ${ }^{1,3}$ and Muhammad Shafiq ${ }^{1}$ (i) \\ 1 Alamoudi Water Research Chair, King Saud University, P.O. Box 2460, Riyadh 11451, Saudi Arabia; \\ alazba@ksu.edu.sa (A.A.A.); msrana@ksu.edu.sa (M.S.) \\ 2 Department of Environmental Sciences, COMSATS University Islamabad, Abbottabad Campus, \\ University Road, Abbottabad 22060, Pakistan \\ 3 Agricultural Engineering Department, King Saud University, P.O. Box 2460, Riyadh 11451, Saudi Arabia \\ * Correspondence: mtamin@ksu.edu.sa; Tel.: +966-59000963
}

Citation: Amin, M.T.; Alazba, A.A.; Shafiq, M. Comparative Removal of Lead and Nickel Ions onto Nanofibrous Sheet of Activated Polyacrylonitrile in Batch Adsorption and Application of Conventional Kinetic and Isotherm Models. Membranes 2021, 11, 10. https://dx.doi.org/10.3390/ membranes 11010010

Received: 4 November 2020 Accepted: 18 December 2020 Published: 23 December 2020

Publisher's Note: MDPI stays neutral with regard to jurisdictional claims in published maps and institutional affiliations.

Copyright: () 2020 by the authors. Licensee MDPI, Basel, Switzerland. This article is an open access article distributed under the terms and conditions of the Creative Commons Attribution (CC BY) license (https://creativecommons.org/ licenses/by/4.0/).

\begin{abstract}
We investigated the adsorption of lead $\left(\mathrm{Pb}^{2+}\right)$ and nickel $\left(\mathrm{Ni}^{2+}\right)$ ions by electrospun membranes of polyacrylonitrile (PAN) nanofiber activated with $\mathrm{NaHCO}_{3}$ (PANmod). Analysis by Fourier-transform infrared spectrometry (FTIR), field emission scanning electron microscopy (FE-SEM), and energy dispersive X-ray spectroscopy (EDX) validated the functionalization of PAN nanofibers with $\mathrm{NaHCO}_{3}$, and the successful agglomeration of $\mathrm{Pb}^{2+}$ and $\mathrm{Ni}^{2+}$ onto PANmod. After a rapid uptake of the heavy metal ions (15 $\mathrm{min}$ ), the equilibrium contact time was attained (60 $\mathrm{min}$ ) following a linear increase of both adsorption capacity and removal efficiency. PANmod showed a better affinity for $\mathrm{Ni}^{2+}$ than $\mathrm{Pb}^{2+}$. The adsorption on PANmod was best described by the pseudosecond-order kinetic model for both studied models, supporting chemisorption. By varying the solution $\mathrm{pH}$ from 2.0 to 9.0, we found that the adsorption capacity followed an increasing trend, reaching a maximum at the $\mathrm{pH}$ of 7.0. Despite increasing adsorption capacities, the removal efficiency of both heavy metal ions exhibited a decreasing trend with increase in initial concentrations. The amount of PANmod directly affects the removal efficiency, with 0.7 and $0.2 \mathrm{~g}$ being the optimum dose for maximum uptake of $\mathrm{Pb}^{2+}$ and $\mathrm{Ni}^{2+}$, respectively. The Langmuir model fitted well the $\mathrm{Pb}^{2+}$ adsorption data suggesting monolayer adsorption, and the Freundlich model perfectly fitted the $\mathrm{Ni}^{2+}$ adsorption data, indicating heterogeneous adsorption. The estimated values of the mean free energy of adsorption in the D-R isotherm indicated a physical adsorption of both heavy metal ions into the surface of the PANmod.
\end{abstract}

Keywords: adsorption capacity; electrospinning; Langmuir and Freundlich; PANmod; physisorption; pseudo-second-order

\section{Introduction}

Rapid industrial development and urbanization introduced large amount of waste effluents into various environmental compartments [1]. Those effluents contain large amounts of toxic metals/metalloids, drastically polluting the ecosystem. Among toxic metals, nickel $\left(\mathrm{Ni}^{2+}\right)$ and lead $\left(\mathrm{Pb}^{2+}\right)$ abound in industrial wastewaters produced during mining, battery and machinery manufacturing, mineral processing, metal coating, and cable sheathing, as well as by steam electric power plants and stainless steel alloys, plating and tanning industries [2,3]. Elevated levels of the non-biodegradable $\mathrm{Ni}^{2+}$ and $\mathrm{Pb}^{2+}$ ions in freshwater sources pose a significant threat to animal and human health, because they accumulate in living tissues through the food chain [4]. Exposure to metals/metalloids may induce severe deterioration in human health including memory loss, cardiovascular 
disease, abdominal pain, weakness, chronic bronchitis and cancer of the lung [5]. Therefore, in pursuance of a pollution-free ecosystem, these toxic metals/metalloids should be eliminated from industrial wastewater before it is discharged into freshwater resources.

Various wastewater treatment techniques such as reverse osmosis, ion exchange, chemical precipitation, electrodialysis, chemical coagulation, solvent extraction and adsorption processes have been employed to remove metals/metalloids from industrial wastewater [6-10]. However, most of these methods are either inefficient or costly [11]. Adsorption technology is emerging as the best technology for wastewater purification due to its simplicity of design, low cost, ease in operation, reduced output of harmful sludge, insensitivity to pollutants, reduced energy consumption, high effectivity and environment compatibility [12]. The adsorption efficiency is directly linked to the materials used in the adsorption process. The most important characteristics of the adsorbent are higher surface area, porosity and the chemical structure $[13,14]$. In addition, the surface polarity and chemical composition of the adsorbent can affect the attraction forces between adsorbent and adsorbate [15]. Therefore, selection of an appropriate adsorbent is of critical importance. Polymer nanofiber membrane-based adsorbents prepared by the electrospinning technique have been widely used for metals/metalloids removal from wastewater, due to their unique properties of high porosity, specific pattern of fine pores, and larger surface area $[16,17]$. Polyacrylonitrile (PAN) is a synthetic semi-crystalline organic polymer which does not melt under normal condition, but does at $300^{\circ} \mathrm{C}$ [18]. Furthermore, PAN can be electrospun due to its optimum stability, great chemical resistance, high solubility, and great mechanical strength [19-21]. Because of these unique properties, PAN is a potential candidate as a nano-fibrous adsorbent for wastewater treatment [22]. The adsorption efficiency of membranes made of PAN can be increased by adding various types of nanomaterials to the PAN/DMF solution before electrospinning, or by applying certain chemical treatments after fabrication to increase its functionality $[20,23]$. The main objective of treating nano-fibrous membranes with chemical treatments or cross-linking of the nano fibrous membrane is that, under specific conditions, the functional groups on the surface of nanofibers are modified into an appropriate form, depending on the nature of the adsorbate which may be involved in chemical reactions with complexation agents of metal ions [24]. Researchers have been using chemically treated nanofiber membranes such as PAN/EDTA [19], and PAN/NaOH-NaHCO 3 [25], for removal of dyes and metals/metalloids ions since the last decade. It has been assumed that the functionalization of the PAN nanofibers surface is the most important factor for improving the adsorption efficiency of adsorbents used in the elimination of metal ions.

The electrospun sheet of a PAN nanofiber treated with $\mathrm{NaHCO}_{3}$ (PANmod) has not yet been tested for adsorption of heavy metal ions from aqueous systems. This endeavor is the focus of the current study. Our main objective was to functionalize and characterize the PANmod, and determine its feasibility as an efficient adsorbent for the removal of $\mathrm{Pb}^{2+}$ and $\mathrm{Ni}^{2+}$ from aqueous solutions. Furthermore, we evaluated adsorption performance employing conventional kinetics and isotherm models.

\section{Materials and Methods}

\subsection{Fabrication and Characterization of the PANmod}

We prepared a $10 \%(w / v)$ solution of polymer PAN $\left(\left(\mathrm{C}_{3} \mathrm{H}_{3} \mathrm{~N}\right)_{n}\right.$; Sigma-Aldrich, St. Louis, MO, USA) and solvent dimethylformamide (DMF, $\mathrm{C}_{3} \mathrm{H}_{7} \mathrm{NO}$; Sigma-Aldrich, $99.8 \%$ ), which was homogenized at room temperature using a magnetic stirrer (IKA Werke $\mathrm{GmbH}$, Staufen, Germany) for approximately $12 \mathrm{~h}$. The resulting mixture was injected to an electrospinning device (NanoNC Electrospray system, Seoul, Korea) at a flow rate of $1 \mathrm{~mL} \mathrm{~h}^{-1}$ using a $5 \mathrm{~mL}$ glass syringe. The distance between the needle tip and the grounded metal collector was set at $15 \mathrm{~cm}$ and the electrospinning device was operated at high voltage $(15 \mathrm{kV})$ supplied by a high voltage generator (Model: ESN-HV30). The resulting sheet was prepared in a rectangular shape $\left(5 \times 7 \mathrm{~cm}^{2}\right)$, dipped in $150 \mathrm{~mL}$ of $15 \%$ $\mathrm{NaOH}$ solution $\left(60 \mathrm{~min}, 60^{\circ} \mathrm{C}\right)$, and then washed several times with distilled water. Next, 
to neutralize the excess amount of base, the sheet was immersed in $100 \mathrm{~mL}$ of $1.0 \mathrm{M} \mathrm{HCl}$ solution. Subsequently, the hydrolyzed sheet was treated with $100 \mathrm{~mL}$ of $10 \% \mathrm{NaHCO}_{3}$ solution for $6 \mathrm{~h}$, to prepare the final product. The fabricated PANmod sheet was cut into small pieces, to be used as an adsorbent for heavy metal ions. Its chemical groups and surface morphology were examined by Fourier-transform infrared spectrometry (FTIR) (Vertex 70 Bruker, Karlsruhe, Germany), field emission scanning electron microscopy (FESEM) (JSM-7600 JEOL, Tokyo, Japan) and energy dispersive X-ray spectroscopy (EDX) (Inca software installed inside FE-SEM).

\subsection{Experimental Setup and Analysis}

Stock solutions of $\mathrm{Pb}^{2+}\left(1000 \mathrm{mg} \mathrm{L}^{-1}\right)$ and $\mathrm{Ni}^{2+}\left(1000 \mathrm{mg} \mathrm{L}^{-1}\right)$ were prepared from analytical reagent grade precursors, lead nitrate $\left(\mathrm{Pb}\left(\mathrm{NO}_{3}\right)_{2}\right.$; Tianjin Benchmark Chemical Reagent Co., Ltd. Tianjin, China) and nickel nitrate hexahyhydrate $\left(\mathrm{Ni}\left(\mathrm{NO}_{3}\right)_{2} \cdot 6 \mathrm{H}_{2} \mathrm{O}\right.$; Tianjin Benchmark Chemical Reagent Co., Ltd. Tianjin, China), respectively. $1000 \mathrm{mg}$ of each precursor was dissolved in $1.0 \mathrm{~L}$ of deionized water. Each stock solution was further diluted, to achieve the initial concentrations of $\mathrm{Pb}^{2+}$ or $\mathrm{Ni}^{2+}$ required in different batch tests; the solution $\mathrm{pH}$ was maintained at various fixed values (2-9) by using either diluted sodium hydroxide $(\mathrm{NaOH})$ or diluted hydrochloric acid $(\mathrm{HCl}) .50 \mathrm{~mL}$ of metal solution with different initial concentrations $\left(5-50 \mathrm{mg} \mathrm{L}^{-1}\right)$ were agitated for fixed time intervals (5-300 $\mathrm{min}$ ) in a temperature-controlled shaker (Wise Cube orbital, Wisd. ThermoStable IS-20; Daihan Scientific Co. Ltd., Wonju, South Korea), adding the amount of PANmod to achieve the required dose $(0.1-0.9 \mathrm{~g})$ in each batch trial. After shaking them in conical flasks $(100 \mathrm{~mL})$ for a predetermined time, the resultant mixture was filtered through $0.45 \mu \mathrm{m}$ filter paper (Whatman ${ }^{\mathrm{TM}}$ ) and the residual concentration of metal was determined using flame atomic absorption spectrometry (FAAS, Thermo Scientific, ICE 3000 Series, Cambridge, United Kingdom). The amount of metal uptake at time $t$, that is the adsorption capacity $\left(q_{t}, \mathrm{mg} \mathrm{g}^{-1}\right)$ and the effective of the adsorption of metal ions into PANmod were determined using the following equations:

$$
\begin{gathered}
\text { Adsorption capacity }=\left(\frac{\left(C_{0}-C_{t}\right) \cdot V}{m}\right) \\
\text { Removal }(\%)=\left(\frac{C_{0}-e}{C_{0}}\right) \times 100,
\end{gathered}
$$

where $C_{\mathrm{o}}\left(\mathrm{mg} \mathrm{L}^{-1}\right)$ is the concentration of either $\mathrm{Pb}^{2+}$ or $\mathrm{Ni}^{2+}$ before the batch adsorption and $C_{e}\left(\mathrm{mg} \mathrm{L}^{-1}\right)$ is the equilibrium concentration of either $\mathrm{Pb}^{2+}$ or $\mathrm{Ni}^{2+} \cdot C_{t}\left(\mathrm{mg} \mathrm{L}^{-1}\right)$ is the concentration of either metal ions after sorption for a specified contact time and corresponds to $q_{t}\left(\mathrm{mg} \mathrm{g}^{-1}\right)$ for evaluating the kinetics of the adsorption process. $V(\mathrm{~L})$ is the volume of the metal ions' solution and $m(\mathrm{~g})$ is the mass of the PANmod. For the isotherm models, the equilibrium adsorption capacity, $q_{e}\left(\mathrm{mg} \mathrm{g}^{-1}\right)$, was evaluated from Equation (1), corresponding to the equilibrium concentration of metal ions measured at equilibrium contact time $C_{e}\left(\mathrm{mg} \mathrm{L}^{-1}\right)$.

\section{Results and Discussion}

\subsection{PANmod Characteristcs}

\subsubsection{FTIR Analysis}

To investigate modification in the functional groups and surface chemistry of PAN nanofibers, pristine and $\mathrm{Ni}^{2+}$ and $\mathrm{Pb}^{2+}$ loaded PANmod samples were analyzed by the FTIR technique; the acquired spectra are presented in Figure 1 . The sharp peak at $1095 \mathrm{~cm}^{-1}$ is ascribed as stretching vibrations of the $\mathrm{C}-\mathrm{O}$ group, whereas the peaks at 1225 and $1360 \mathrm{~cm}^{-1}$ are designated as vibrations of $\mathrm{C}-\mathrm{O}-\mathrm{C}$ and $\mathrm{C}-\mathrm{OH}$, respectively (Figure 1a). Likewise, sharp peaks appearing at 1450, 3319 and $3498 \mathrm{~cm}^{-1}$ reveal the stretching vibrations of $-\mathrm{CH}_{2}-, \mathrm{O}-\mathrm{H}$, and $\mathrm{N}-\mathrm{H}$ groups [26]. The peaks appearing at 1664,2243 , and $2931 \mathrm{~cm}^{-1}$ correspond to stretching vibrations of the $\mathrm{C}=\mathrm{O}, \mathrm{C}-\mathrm{N}$, and $\mathrm{C}-\mathrm{H}$ groups, 
respectively [27]. After the PAN nanofiber was treated with $\mathrm{NaHCO}_{3}$, the spectral peaks appearing at 1095, 1664 and $2931 \mathrm{~cm}^{-1}$ shifted to the lower wave number positions 1074 , 1662 , and $2925 \mathrm{~cm}^{-1}$, respectively, while other peaks such as 1225,1360 , and $3319 \mathrm{~cm}^{-1}$ shifted to the higher wave number positions 1240,1362, and $3321 \mathrm{~cm}^{-1}$, respectively [28].

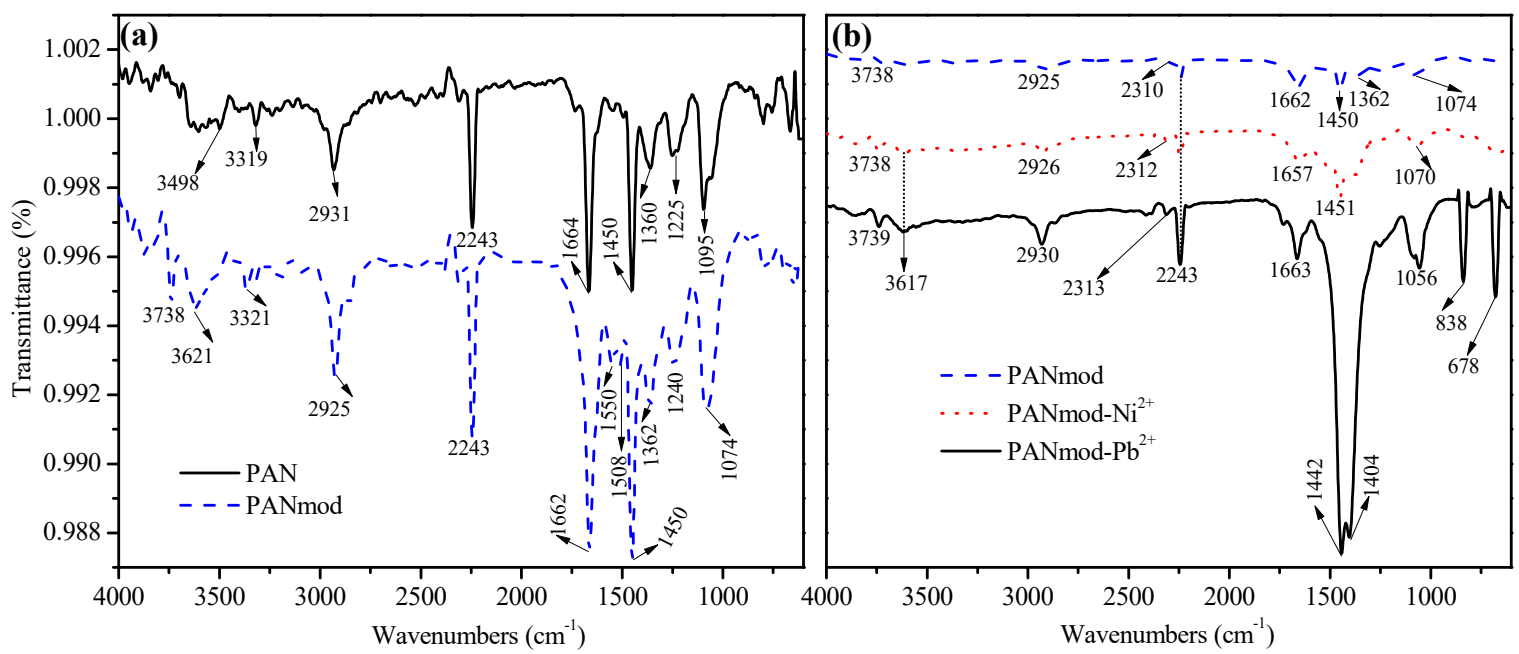

Figure 1. Fourier-transform infrared spectrometry (FTIR) analysis of (a) the polyacrylonitrile (PAN) nanofibers and PAN nanofiber activated with $\mathrm{NaHCO}_{3}$ (PANmod) and (b) PANmod, PANmod-Ni ${ }^{2+}$ and $\mathrm{PANmod}-\mathrm{Pb}^{2+}$.

In addition, new low intensity peaks noted at 1508 and $1550 \mathrm{~cm}^{-1}$ were ascribed to the aromatic N-H secondary amine group [28]; other new peaks appearing around 3621 and $3738 \mathrm{~cm}^{-1}$ were ascribed to stretching vibrations of $\mathrm{O}-\mathrm{H}$ group [29]. These spectral changes indicate the interactions between $\mathrm{PAN}$ nanofibers and $\mathrm{NaHCO}_{3}$ functionalization by the formation of polar interactions between the functional groups of both components. Polar interactions of the functional groups might help in the adsorption of divalent heavy metal ions.

The vibrational spectra of $\mathrm{Ni}^{2+}$ and $\mathrm{Pb}^{2+}$ loaded PANmod are shown in Figure $1 \mathrm{~b}$. In $\mathrm{Ni}^{2+}$ loaded PANmod, the $1070 \mathrm{~cm}^{-1}$ spectral peak is ascribed to $\mathrm{C}-\mathrm{O}$ bonds. The vibrational spectral peaks at $1451,1657,2312,2926$, and $3738 \mathrm{~cm}^{-1}$ are ascribed to the $-\mathrm{CH}_{2}-, \mathrm{C}=\mathrm{O}, \mathrm{C}-\mathrm{H}$, and $\mathrm{O}-\mathrm{H}$ groups, respectively [27]. In the $\mathrm{Pb}^{2+}$ loaded PANmod sample spectra, some peaks were shifted and some new peaks were observed, when compared to PANmod. The shifted spectral features are the 1056, 1404, 1442, 1663, 2313, 2930, and $3739 \mathrm{~cm}^{-1}$ peaks. Moreover, the two new peak positions around 678, and $838 \mathrm{~cm}^{-1}$ were ascribed to metal $\left(\mathrm{M}=\mathrm{Ni}^{2+}, \mathrm{Pb}^{2+}\right)$ and oxygen $(\mathrm{M}-\mathrm{O}$ or $\mathrm{M}-\mathrm{O}-\mathrm{M})$ interactions [30]. FTIR spectral analysis revealed a successful adsorption of $\mathrm{Ni}^{2+}$ and $\mathrm{Pb}^{2+}$ into the PANmod surface.

\subsubsection{FE-SEM and EDX Analysis}

We investigated by FE-SEM and EDX the changes in elemental composition and morphological features of the pure PAN nanofibers, as well as pristine and $\mathrm{Ni}^{2+}$ and $\mathrm{Pb}^{2+}$ loaded PANmod (Figure 2). Very smooth, cylindrical, randomly arranged, and beads-free nanofibers of pure PAN are clearly seen in Figure 2a. Their EDX analysis (Figure 2a*) reveal that the $\mathrm{C}$ and $\mathrm{O}$ content in these nanofibers are $96.56 \%$ and $3.44 \%$, respectively. The rough and porous surfaces of the PANmod nanofibers are clearly shown by the FE-SEM image in Figure 2b; the EDX analysis (Figure $2 b^{*}$ ) of the same nanofibers reveals their successful functionalization. Additionally, the elemental composition of the PANmod show that the contents of $\mathrm{C}, \mathrm{N}, \mathrm{O}, \mathrm{Na}$, and $\mathrm{Cl}$ are $62.90,31.90,2.54,1.47$, and $1.19 \%$, respectively. 

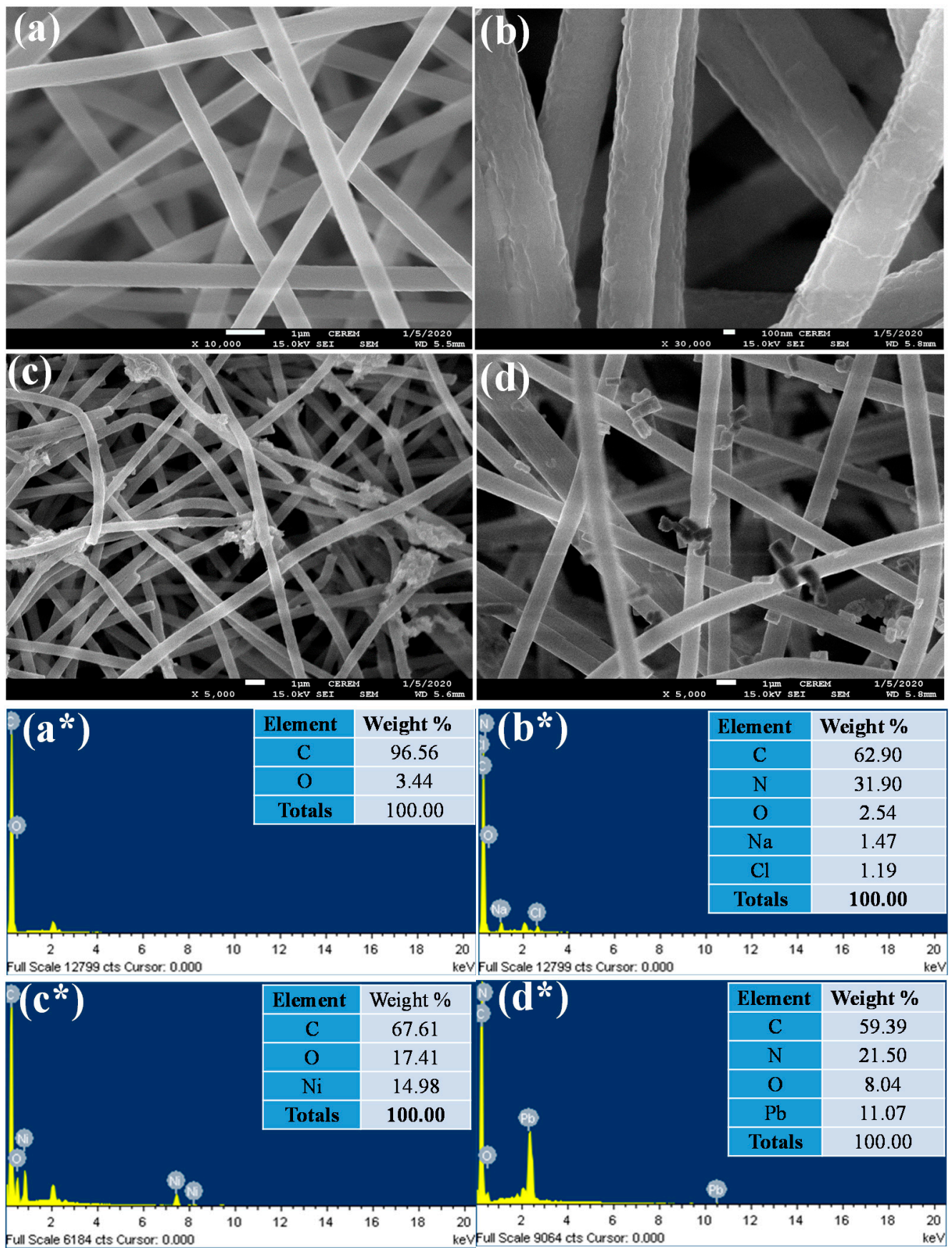

Figure 2. Field emission scanning electron microscopy (FE-SEM) and energy dispersive X-ray spectroscopy (EDX) spectra of PAN nanofibers $\left(\mathbf{a}, \mathbf{a}^{*}\right)$, PANmod $\left(\mathbf{b}, \mathbf{b}^{*}\right)$, PANmod- $\mathrm{Ni}^{2+}\left(\mathbf{c}, \mathbf{c}^{*}\right)$, and PANmod- $\mathrm{Pb}^{2+}\left(\mathbf{d}, \mathbf{d}^{*}\right)$.

Furthermore, the agglomeration of $\mathrm{Ni}^{2+}$ onto nanofibers can clearly be seen in the FE-SEM image of the post-adsorption $\mathrm{Ni}^{2+}$ loaded PANmod samples (Figure 2c). The EDX analysis of $\mathrm{Ni}^{2+}$ loaded PANmod (Figure $2 \mathrm{c}^{*}$ ) shows an increase in $\mathrm{C}(67.61 \%)$ and $\mathrm{O}$ contents $(17.41 \%)$, compared with pristine nanofibers; $14.98 \%$ of $\mathrm{Ni}^{2+}$ are also observed, suggesting the adsorption of $\mathrm{Ni}^{2+}$ on these nanofibers. Similarly, the FE-SEM image of the post-adsorption $\mathrm{Pb}^{2+}$ loaded PANmod reveals very small particles attached to the nanofibers, probably $\mathrm{Pb}^{2+}$ (Figure 2d). Interestingly, the EDX spectrogram of the PANmod$\mathrm{Pb}^{2+}$ (Figure $\left.2 \mathrm{~d}^{*}\right)$ shows a reduction in $\mathrm{C}(59.39 \%)$ and $\mathrm{N}$ contents $(21.50 \%)$, and an increase in $\mathrm{O}$ content $(8.04 \%), 11.07 \%$ of $\mathrm{Pb}^{2+}$ suggests the successful adsorption of $\mathrm{Pb}^{2+}$ on PANmod- 
$\mathrm{Pb}^{2+}$. This analysis reveals that the functionalization of the PAN nanofibers with $\mathrm{NaHCO}_{3}$ is quite beneficial for the adsorption of $\mathrm{Ni}^{2+}$ and $\mathrm{Pb}^{2+}$ metal ions.

3.2. Influence of the Contact Time and Fitting of Kinetic Models to the Adsorption Data of Both Heavy Metal Ions

We estimated the equilibrium contact time for both heavy metal ions by performing time-series batch experiments; Figure 3 shows the variations in both the adsorption capacity and removal efficiency by PANmod at different initial concentrations of $\mathrm{Pb}^{2+}$ and $\mathrm{Ni}^{2+}$. The solution $\mathrm{pH}$ was maintained at 5.0 and 7.0 for $\mathrm{Pb}^{2+}$ and $\mathrm{Ni}^{2+}$, respectively, by using a fixed amount $(0.5 \mathrm{~g})$ of PANmod. Our observations clearly demonstrate a very rapid uptake of both heavy metal ions at any tested initial concentration, during immediate contact with PANmod. In the first 15 min of contact time, one can see almost $70-80 \%$ (Figure 3a) and $90 \%$ (Figure $3 \mathrm{~b}$ ) of the maximum removal efficiency of, respectively, $\mathrm{Pb}^{2+}$ and $\mathrm{Ni}^{2+}$ by PANmod. This could be the result of adsorbed metal ions accumulation on the unused surface and free active sites of the PANmod. After rapid uptake of the adsorbate, a nearly linear increase can be observed in both the adsorption capacity and the removal efficiency, equilibrium being attained at about $60 \mathrm{~min}$ since contact started. An additional $4 \mathrm{~h}$ of contact yielded insignificant $(p=0.01)$ effects on the adsorption performance (Figure 3 ), due to the saturation of the absorption sites of the PANmod. For $20 \mathrm{mg} \mathrm{L}^{-1}$ initial metal concentration, the maximum adsorption capacity at $60 \mathrm{~min}$ was 12.7 and $37.4 \mathrm{mg} \mathrm{g}^{-1}$ with corresponding removal efficiency of 32 and $92 \%$ for $\mathrm{Pb}^{2+}$ and $\mathrm{Ni}^{2+}$, respectively. This indicates a dominant effect and better efficiency of the absorption performance of the PANmod for $\mathrm{Ni}^{2+}$, compared to $\mathrm{Pb}^{2+}$.
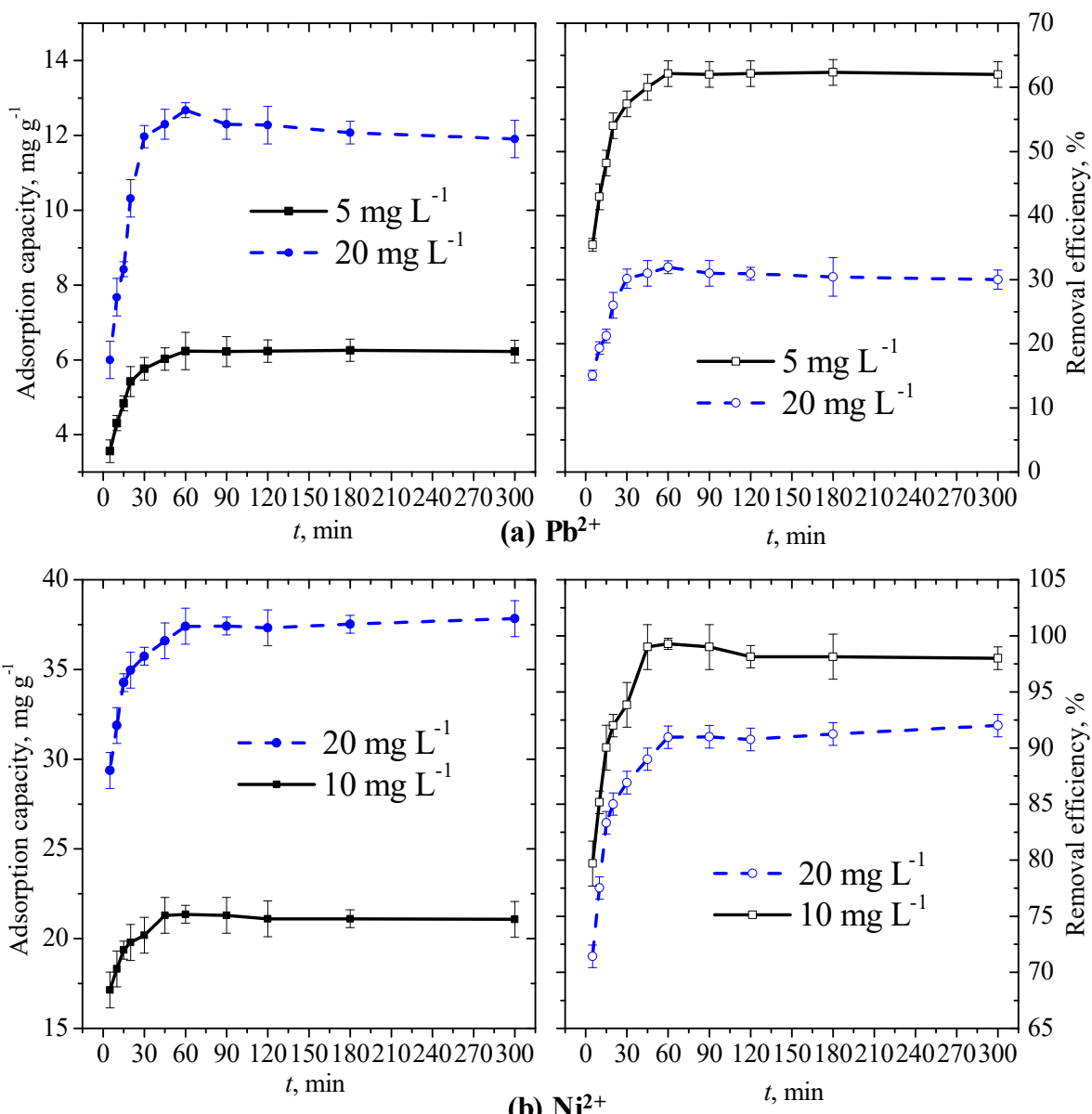

Figure 3. Variations with time of the adsorption capacity and removal efficiency of (a) $\mathrm{Pb}^{2+}$ and (b) $\mathrm{Ni}^{2+}$ by PANmod. 
Conventional kinetic models were applied to the data collected using the heavy metal ions adsorption on PANmod; and these included the pseudo-first-order (PFO, Equation (3)), pseudo-second-order (PSO, Equation (4)), intraparticle diffusion of Weber and Morris (IDWM, Equation (5)), and Elovich (Equation (6)) kinetic models.

$$
\begin{gathered}
q_{t}=q_{e}\left(1-\exp \left(-k_{1} t\right)\right) \\
q_{t}=\frac{q_{e}^{2} k_{2} \cdot t}{q_{e} k_{2} \cdot t+1} \\
q_{t}=K_{i p} t^{1 / 2}+C \\
q_{t}=\frac{1}{\beta} \ln (1+\alpha \beta t)
\end{gathered}
$$

In the above equations, $q_{t}\left(\mathrm{mg} \mathrm{g}^{-1}\right)$ is the amount of adsorbed $\mathrm{Pb}^{2+}$ or $\mathrm{Ni}^{2+}$, while $q_{e}\left(\mathrm{mg} \mathrm{g}^{-1}\right)$ is the equilibrium adsorption capacity of the PANmod for metal ions, $k_{1}\left(\mathrm{~min}^{-1}\right)$ is the rate constant for the PFO kinetic model and $k_{2}\left(\mathrm{mg} \mathrm{g}^{-1} \mathrm{~min}^{-1}\right)$ for the PSO kinetic model. The estimated rate constant in the PSO kinetic model is further used to evaluate the initial adsorption rate $h\left(k_{2} q_{e}^{2} ; \mathrm{mg} \mathrm{g}^{-1} \mathrm{~min}^{-1}\right)$. For the ID-WM kinetic model, the rate constant is expressed by $K_{i p}\left(\mathrm{mg} \mathrm{g}^{-1} \mathrm{~min}^{1 / 2}\right)$ and the boundary-layer thickness by $C\left(\mathrm{mg} \mathrm{g}^{-1}\right)$. In the Elovich kinetic model, $\alpha\left(\mathrm{mg} \mathrm{g}^{-1} \mathrm{~min}^{-1}\right)$ is the initial adsorption rate constant and $\beta\left(\mathrm{g} \mathrm{mg}^{-1}\right)$ expresses the chemisorption activation energy. Figure 4 shows the PSO and Elovich kinetic models fitting of the adsorption data for $\mathrm{Pb}^{2+}$ and $\mathrm{Ni}^{2+}$ with initial concentrations of 10 and $20 \mathrm{mg} \mathrm{L}^{-1}$; both the nonlinear and linearized approaches were used. The solution $\mathrm{pH}$ was maintained at $5 \pm 0.2$ and $7 \pm 0.3$ for $\mathrm{Pb}^{2+}$ and $\mathrm{Ni}^{2+}$, respectively, and the dose of PANmod was $0.5 \mathrm{~g}$. Table 1 presents the values of the related parameters in all nonlinear models as estimated using the OriginPro 8.5 software at different initial concentrations of both metal ions.
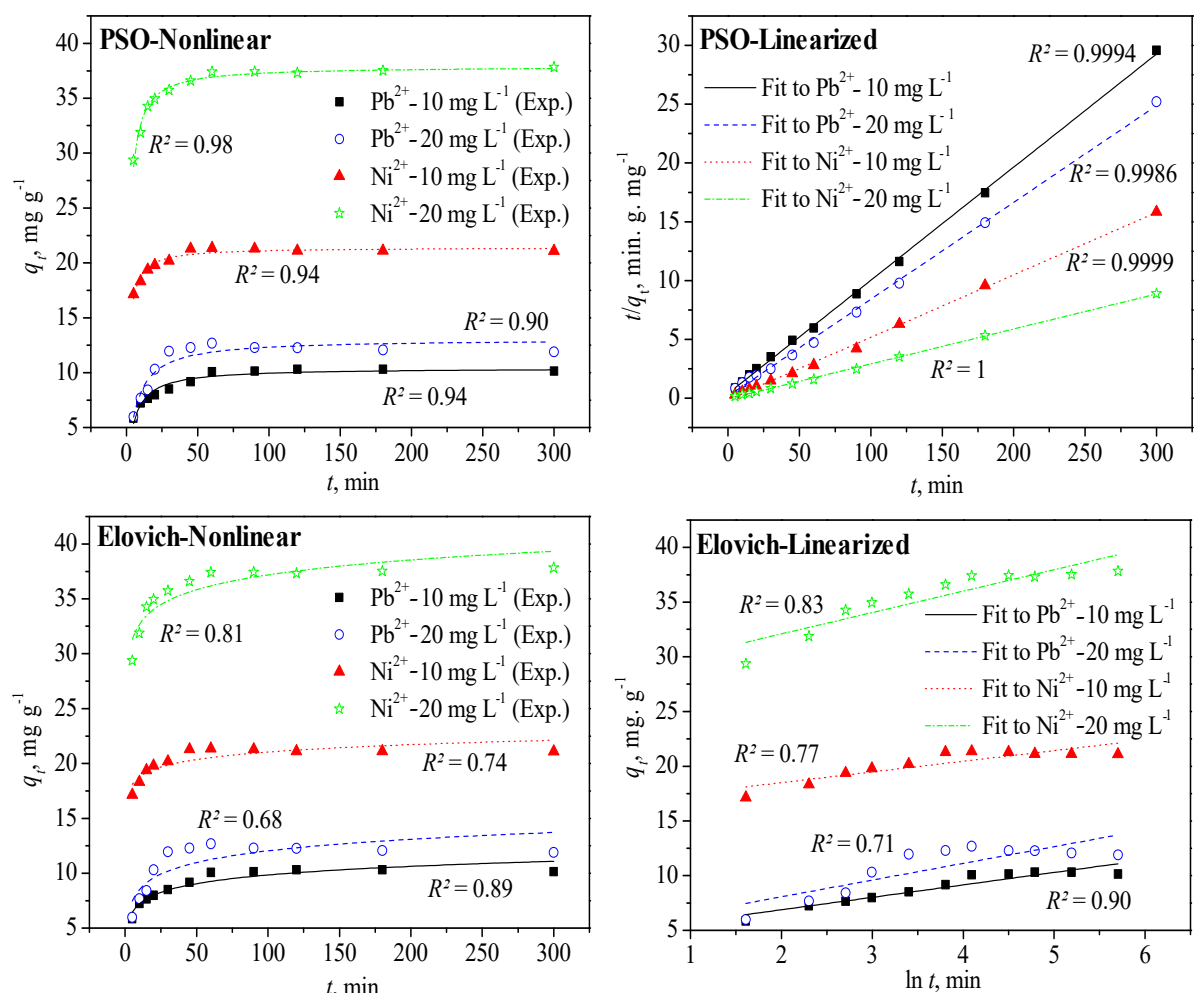

Figure 4. Fitting of the pseudo-second-order (PSO) and Elovich kinetic models to the adsorption data of $\mathrm{Pb}^{2+}$ and $\mathrm{Ni}^{2+}$ on PANmod at different initial concentrations. 
Table 1. Parameters of the nonlinear pseudo-first-order (PFO), pseudo-second-order (PSO), intraparticle diffusion of Weber and Morris (ID-WM), and Elovich kinetics models for the adsorption of $\mathrm{Pb}^{2+}$ and $\mathrm{Ni}^{2+}$ onto PANmod (Contact time $=0-300 \mathrm{~min}$, PANmod dose $=0.5 \mathrm{~g}, \mathrm{pH}=5 \pm 0.2$ and $7 \pm 0.2$ for $\mathrm{Pb}^{2+}$ and $\mathrm{Ni}^{2+}$, respectively).

\begin{tabular}{|c|c|c|c|c|c|c|c|c|}
\hline \multirow{3}{*}{$\begin{array}{l}\text { Kinetic } \\
\text { Model }\end{array}$} & \multirow{3}{*}{ Parameter } & \multicolumn{7}{|c|}{ Initial Metal Conc. $\left(\mathrm{mg} \mathrm{L}^{-1}\right)$} \\
\hline & & \multicolumn{4}{|c|}{$\mathrm{Pb}^{2+}$} & \multicolumn{3}{|c|}{$\mathrm{Ni}^{2+}$} \\
\hline & & 5 & 10 & 15 & 20 & 10 & 15 & 20 \\
\hline & $\begin{array}{c}q_{\mathrm{e} \exp }(\mathrm{mg} \\
\left.\mathrm{g}^{-1}\right)\end{array}$ & 6.24 & 10.07 & 12.51 & 12.67 & 21.36 & 29.43 & 37.41 \\
\hline \multirow{3}{*}{ PFO } & $\begin{array}{c}q_{e c a l}(\mathrm{mg} \\
\left.\mathrm{g}^{-1}\right)\end{array}$ & 6.11 & 9.73 & 12.21 & 12.24 & 20.68 & 28.5 & 36.51 \\
\hline & $k_{1}\left(\min ^{-1}\right)$ & 0.13 & 0.13 & 0.14 & 0.099 & 0.31 & 0.31 & 0.29 \\
\hline & $R^{2}$ & 0.9 & 0.74 & 0.92 & 0.93 & 0.62 & 0.65 & 0.7 \\
\hline \multirow{4}{*}{ PSO } & $\begin{array}{c}q_{\text {e cal }}(\mathrm{mg} \\
\left.\mathrm{g}^{-1}\right)\end{array}$ & 6.49 & 10.42 & 12.96 & 13.05 & 21.4 & 29.5 & 37.89 \\
\hline & $\begin{array}{c}k_{2}\left(\mathrm{~g} \mathrm{mg}^{-1}\right. \\
\left.\min ^{-1}\right)\end{array}$ & 0.035 & 0.02 & 0.019 & 0.013 & 0.034 & 0.024 & 0.017 \\
\hline & $\begin{array}{c}h\left(\mathrm{mg} \mathrm{g}^{-1}\right. \\
\left.\min ^{-1}\right)\end{array}$ & 1.47 & 2.17 & 3.19 & 2.21 & 15.57 & 20.89 & 24.41 \\
\hline & $R^{2}$ & 0.98 & 0.94 & 0.99 & 0.9 & 0.94 & 0.95 & 0.98 \\
\hline \multirow{3}{*}{ ID-WM } & $\begin{array}{c}K_{i p}\left(\mathrm{mg} \mathrm{g}^{-1}\right. \\
\left.\min ^{1 / 2}\right)\end{array}$ & 0.15 & 0.27 & 0.28 & 0.33 & 0.21 & 0.31 & 0.45 \\
\hline & $C\left(\mathrm{mg} \mathrm{g}^{-1}\right)$ & 4.41 & 6.78 & 9.07 & 8.18 & 18.53 & 25.38 & 32.05 \\
\hline & $R^{2}$ & 0.51 & 0.64 & 0.49 & 0.6 & 0.46 & 0.5 & 0.55 \\
\hline \multirow{3}{*}{ Elovich } & $\begin{array}{c}\alpha\left(\operatorname{mg~g}^{-1}\right. \\
\left.\min ^{-1}\right)\end{array}$ & 70.69 & 65.3 & 241.7 & 41.1 & $2.31 \times 10^{7}$ & $1.45 \times 10^{7}$ & $3.57 \times 10^{6}$ \\
\hline & $\beta\left(\mathrm{g} \mathrm{mg}^{-1}\right)$ & 1.51 & 0.88 & 0.8 & 0.66 & 1.03 & 0.72 & 0.51 \\
\hline & $R^{2}$ & 0.79 & 0.89 & 0.77 & 0.68 & 0.74 & 0.78 & 0.81 \\
\hline
\end{tabular}

The PSO kinetic model linearized fitting yielded a perfect fit of the model to the adsorption of both heavy metal ions on PANmod at the initial concentrations tested (10 and $20 \mathrm{mg} \mathrm{L}^{-1}$ ), with a coefficient of determination $\left(R^{2}\right)$ close to unity (1.0). The nonlinear fitting of the PSO kinetic model yielded also a good fitting of the adsorption data with $R^{2}$ in the range $0.90-0.98$, with $\mathrm{Ni}^{2+}$ presenting a relatively good fit compared to the adsorption data of $\mathrm{Pb}^{2+}$, at $20 \mathrm{mg} \mathrm{L}^{-1}$. For the Elovich kinetic model, no significant difference between the $R^{2}$ for nonlinear and linearized fitting was observed, with the linearize fitting yielding somewhat better results than the nonlinear approach. In addition, at $20 \mathrm{mg} \mathrm{L}^{-1}$, the models fitted better the adsorption data for $\mathrm{Ni}^{2+}$ than that of the $\mathrm{Pb}^{2+}$, as was the case in the PSO kinetic model, but at an initial concentration of $10 \mathrm{mg} \mathrm{L}^{-1}$, adsorption data of $\mathrm{Pb}^{2+}$ was better described by the Elovich model that that of $\mathrm{Ni}^{2+}$.

The results presented in Table 1 for nonlinear fitting with conventional kinetic models show that, compared to the other models, the PSO model described the best the adsorption of both studied models on PANmod, based on the calculated $R^{2}$ values (0.9-0.99). The only exception was found for $20 \mathrm{mg} \mathrm{L}^{-1}$ in the case of $\mathrm{Pb}^{2+}$ where the PFO kinetic model proved to be slightly better than the PSO model. This has helped to demonstrate that the chemisorption is the governing mechanism of adsorption involving valence forces due to exchange or sharing of electrons between the metal ions and the PANmod. The estimated adsorption capacities matched well with the experimental values for both PFO and PSO kinetic models with PSO yielding a slightly better agreement than the PFO kinetic model at the equilibrium contact time (60 $\mathrm{min})$, as shown in Table 1 . The rate constant in the PFO kinetic model was not affected by changing the initial metal concentration of both heavy metal ions (except at $20 \mathrm{mg} \mathrm{L}^{-1}$ of $\mathrm{Pb}^{2+}$ ) with higher values for $\mathrm{Ni}^{2+}$, compared to $\mathrm{Pb}^{2+}$ (Table 1). 
For the PSO kinetic model, the rate constant reduced to almost half for both heavy metal ions as their initial concentration was doubled, i.e., 10 to $20 \mathrm{mg} \mathrm{L}^{-1}$, with $\mathrm{Ni}^{2+}$ showing higher $k_{2}$ values than $\mathrm{Pb}^{2+}$ at equal initial concentrations. The initial adsorption rate was much higher for $\mathrm{Ni}^{2+}$ compared with $\mathrm{Pb}^{2+}(h$, Table 1$)$, and increased with initial metal concentrations increase for both types of ions. The ID-WM kinetic model did not fit the adsorption data well for neither of the ion types $\left(R^{2}\right.$ ranged between 0.46 and 0.64 , at initial concentrations of 5 to $20 \mathrm{mg} \mathrm{L}^{-1}$ ). Both rate constant and boundary-layer thickness increased as the initial metal concentrations increased, exhibiting higher values for $\mathrm{Ni}^{2+}$ compared to $\mathrm{Pb}^{2+}$ at equal initial concentrations, with the exception of $K_{i p}$ at $10 \mathrm{mg} \mathrm{L}^{-1}$ (Table 1). The Elovich kinetic model fitted reasonably the adsorption data on PANmod for both types of ions, for all initial concentrations, as reflected by the $R^{2}$ values in Table 1.

\subsection{Influence of the Solution $\mathrm{pH}$, Initial Ion Concentration, and Dose of Adsorbent on Adsorption Performance and Regeneration of PANmod}

The variation in absorption capacity and removal of heavy metal ions obtained by changing the $\mathrm{pH}(2-9)$ of the metal solution is shown in Figure 5a. The bath test was conducted at the equilibrium contact time $(60 \mathrm{~min})$ using the adsorbent dose of $0.5 \mathrm{~g}$ of PANmod and 10 and $20 \mathrm{mg} \mathrm{L}^{-1}$ of $\mathrm{Pb}^{2+}$ and $\mathrm{Ni}^{2+}$, respectively, as initial ion concentrations. The excess $\mathrm{H}^{+}$created a competition of absorb on the PANmod surface, with divalent $\mathrm{Pb}^{2+}$ and $\mathrm{Ni}^{2+}[31,32]$ resulting a very low uptake for both ion types at low $\mathrm{pH}$ values. The maximum adsorption capacity of nearly 15 and $60 \mathrm{mg} \mathrm{g}^{-1}$ for $\mathrm{Pb}^{2+}$ and $\mathrm{Ni}^{2+}$, respectively, was found at a solution $\mathrm{pH}$ of 7.0, following a trend of increasing adsorption capacity with increasing $\mathrm{pH}$ due to the lowered amount of $\mathrm{H}^{+}$and reduced competition for divalent $\mathrm{Pb}^{2+}$ and $\mathrm{Ni}^{2+}$ to absorb on the PANmod surface [32,33]. Subsequently, a decrease in metal uptake indicated the $\mathrm{pH}$ of 7.0 as optimum value, as shown in Figure 5a. The percentage removal, after following an increasing trend for both ion types, decreased from $73 \%$ to $21 \%$ and from $91 \%$ to $73 \%$ for $\mathrm{Pb}^{2+}$ and $\mathrm{Ni}^{2+}$, respectively, as the solution $\mathrm{pH}$ increased further from 7.0 to 9.0 .
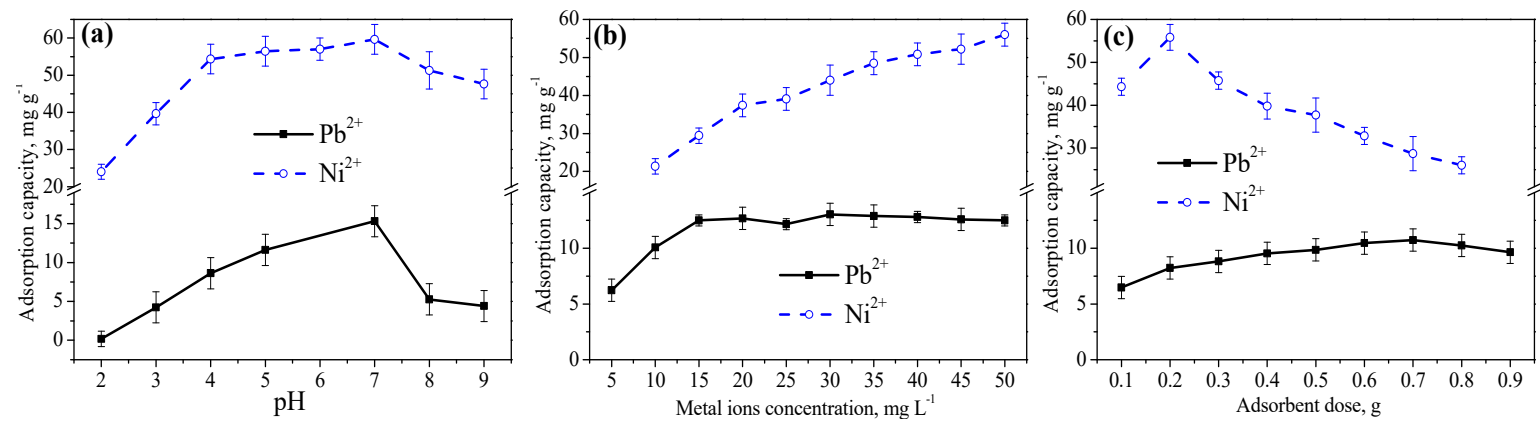

Figure 5. The adsorption capacity of $\mathrm{Pb}^{2+}$ and $\mathrm{Ni}^{2+}$ vs. (a) solution $\mathrm{pH}$, (b) initial metal's concentration, and (c) dose of PANmod.

The absorption potential of the PANmod was optimized for the initial concentration of heavy metal ions; the observed changes are depicted in Figure 5b. An equilibrium contact time of $60 \mathrm{~min}$ was chosen by fixing the dose of PANmod at $0.5 \mathrm{~g}$ while a solution $\mathrm{pH}$ of 5.0 and 7.0 was maintained for $\mathrm{Pb}^{2+}$ and $\mathrm{Ni}^{2+}$, respectively. The PANmod uptake of $\mathrm{Pb}^{2+}$ increased linearly as the initial metal concentration increased from 5 to $20 \mathrm{mg} \mathrm{L}^{-1}$; a further increase in the initial metal concentration did not affect in the adsorption capacity, which remained almost constant at the maximum value of approximately $13 \mathrm{mg} \mathrm{g}^{-1}$, as shown in Figure $5 \mathrm{~b}$. The $\mathrm{Ni}^{2+}$ adsorption, however, continued to increase linearly with its initial concentration increase, attaining the maximum adsorption capacity of $56 \mathrm{mg} \mathrm{g}^{-1}$ at the maximum used value of the initial concentration $\left(50 \mathrm{mg} \mathrm{L}^{-1}\right)$. A concentrated solution with high initial concentration of adsorbate will result in quick adsorption and increased 
adsorption capacity of a fixed amount of the adsorbent (PANmod in this study) due to strong driving forces between divalent metal ions and active adsorbent sites [34,35]. On the other hand, a decreasing trend in the removal efficiency of both types of ions was seen, due to the limited capacity of the fixed amount of PANmod $(0.5 \mathrm{~g})$ and, hence, offering a reduced number of active sites to an increased metal concentration. Finally, a $50 \%$ difference different in percentage removal was seen when the initial concentration of $\mathrm{Pb}^{2+}$ and $\mathrm{Ni}^{2+}$ increased from 5 and 10 to $50 \mathrm{mg} \mathrm{L}^{-1}$, respectively (Figure $5 \mathrm{~b}$ ).

Figure $5 \mathrm{c}$ shows variation in the adsorption capacity due to changes in the amount of PANmod (0.1-0.9 g). The equilibrium contact time was $60 \mathrm{~min}$ for the batch test, and the solution $\mathrm{pH}$ was maintained at 5.0 and 7.0, with a fixed initial concentration of 10 and $20 \mathrm{mg} \mathrm{L}^{-1}$, for $\mathrm{Pb}^{2+}$ and $\mathrm{Ni}^{2+}$, respectively. The optimum dose of PANmod, corresponding to a maximum uptake of $\mathrm{Pb}^{2+}$ and $\mathrm{Ni}^{2+}$, was found to be 0.7 and $0.2 \mathrm{~g}$, respectively. A decrease in the adsorption capacity when the adsorbent dose further increased is associated with the high surface area of the PANmod available to absorb a fixed amount of metal ions, that is 10 and $20 \mathrm{mg} \mathrm{L}^{-1}$ for $\mathrm{Pb}^{2+}$ and $\mathrm{Ni}^{2+}$, respectively. The amount of PANmod has a direct effect on the removal efficiency which increased almost linearly and reached $\sim 90 \%$ and about $100 \%$ for $\mathrm{Pb}^{2+}$ and $\mathrm{Ni}^{2+}$, respectively, at the maximum tested value of $0.9 \mathrm{~g}$ of PANmod. The adsorption capacities of both metal ions, as estimated in the current study, using the PANmod is compared with other similar adsorbents in previous studies (Table 2).

Table 2. Comparison of adsorption capacities of PANmod for $\mathrm{Pb}^{2+}$ and $\mathrm{Ni}^{2+}$ with other similar adsorbents.

\begin{tabular}{|c|c|c|c|}
\hline Adsorbent & Contaminant & Maximum Adsorption Capacity, $\mathrm{mg} \mathrm{g}^{-1}$ & Reference \\
\hline $\mathrm{PAN}_{\bmod }$ & $\mathrm{Pb}^{2+}$ & 15 & This study \\
\hline $\mathrm{PAN}_{\text {mod }}$ & $\mathrm{Ni}^{2+}$ & 60 & This study \\
\hline Polyaniline grafted chitosan & $\mathrm{Pb}^{2+}$ & 16 & [36] \\
\hline APAN nanofiber mat & $\mathrm{Pb}^{2+}$ & 60 & {$[37]$} \\
\hline $\mathrm{PAN} / \mathrm{SiO}_{2}$ composite nanofiber & $\mathrm{Ni}^{2+}$ & 138.7 & [38] \\
\hline ACNFs PAN/ZnO & $\mathrm{Pb}^{2+}$ & 120 & [39] \\
\hline PAN-TiO $2-A P T E S$ & $\mathrm{Ni}^{2+}$ & 147 & [40] \\
\hline P-PAN fibers & $\mathrm{Pb}^{2+}$ & 72.5 & [41] \\
\hline
\end{tabular}

Batch experiments were conducted aiming at the regeneration of the PANmod, considering its reusability and adsorption capacities were estimated for both heavy metal ions in different sets of desorption experiments at different initial solution $\mathrm{pH}$ and temperature. FE-SEM analysis already revealed a strong bonding and affinity between the PANmod surface and the absorbed metal ions $\left(\mathrm{Pb}^{2+}\right.$ and $\left.\mathrm{Ni}^{2+}\right)$, so diluted hydrochloric acid $(0.1 \mathrm{M} \mathrm{HCl})$ was used as eluent in addition to a mild heat treatment inside an oven for $24 \mathrm{~h}$. The amount of desorbed metal ions was high at low solution $\mathrm{pH}(2-5)$ with average desorption rate reaching almost $100 \%$ while the amounts of both metal ions also decreased as temperature increased.

\subsection{Application of Isotherm Models to Adsorption Data of $\mathrm{Pb}^{2+}$ and $\mathrm{Ni}^{2+}$}

The equilibrium data was evaluated with the commonly employed isotherm models and the biosorption process was analyzed. Table 3 shows the original (nonlinear) and linearized mathematical expressions of the two-parameter isotherm models; the Sips and Redlich-Peterson (R-P), among the three-parameter isotherm models are expressed by:

$$
\begin{aligned}
& q_{e}=\frac{q_{m} K_{S} C_{e}^{n_{S}}}{1+K_{S} C_{e}^{n_{S}}} \\
& q_{e}=\frac{q_{m} K_{S} C_{e}^{n_{S}}}{1+K_{S} C_{e}^{n_{S}}}
\end{aligned}
$$


Table 3. Mathematical expressions of the nonlinear and linearized two-parameter isotherm models.

\begin{tabular}{|c|c|c|}
\hline Isotherm & Nonlinear & Linearized \\
\hline Langmuir & $\begin{array}{l}q_{e}=\frac{q_{m} K_{L} C_{e}}{\left(1+K_{L} C_{e}\right)} \\
R_{L}=\left(1+K_{L} C_{0}\right)^{-1}\end{array}$ & $\frac{1}{q_{e}}=\frac{1}{q_{m}}+\left(\frac{1}{q_{m} K_{L}}\right) \frac{1}{C_{e}}$ \\
\hline Freundlich & $q_{e}=K_{F} c_{e} e^{\frac{1}{n}}$ & $\log q_{e}=\log K_{F}+\frac{1}{n} \log C_{e}$ \\
\hline Dubinin-Radus-Kevich & $\begin{array}{l}q_{e}=q_{m} \exp \left(-K_{D R} \varepsilon^{2}\right) \\
\varepsilon=R T \ln \left(1+\frac{1}{C_{e}}\right)\end{array}$ & $\begin{array}{l}\ln q_{e}=\ln q_{m}-K_{D R} \varepsilon^{2} \\
E=\frac{1}{\sqrt{2 K_{D R}}}\end{array}$ \\
\hline Halsey & $q_{e}=\exp \left(\frac{\ln k_{H}-\ln C_{e}}{n_{H}}\right)$ & $\ln q_{e}=\frac{1}{n_{H}} \ln k_{H}-\frac{1}{n_{H}} \ln C_{e}$ \\
\hline Temkin & $q_{e}=\frac{R T}{H_{a d s}} \ln \left(K_{T} C_{e}\right)$ & $q_{e}=\frac{R T}{b_{T}} \ln A_{T}+\frac{R T}{b_{T}} \ln C_{e}$ \\
\hline Harkins-Jura & $q_{e}=\left(\frac{A_{H J}}{B_{H J}-\log C_{e}}\right)^{\frac{1}{2}}$ & $\frac{1}{q_{e}^{2}}=\left(\frac{B_{H J}}{A_{H J}}\right)-\left(\frac{1}{A_{H J}}\right) \log C_{e}$ \\
\hline
\end{tabular}

Parameters $C_{e}\left(\mathrm{mg} \mathrm{L}^{-1}\right)$ and $q_{e}\left(\mathrm{mg} \mathrm{g}^{-1}\right)$, which are used in all expressions of Table 3, represent the residual metal ion concentration in the solution and the corresponding equilibrium adsorption capacity. $q_{m}\left(\mathrm{mg} \mathrm{g}^{-1}\right)$ denotes the estimated maximum adsorption capacity in the Langmuir, Freundlich, Dubinin-Radushkevich (D-R) models (Table 4) and the Sips isotherm model (Equation (7)). The dimensionless separation factor $R_{L}$ (Table 3) in the Langmuir model is used to describe the shape of the isotherm [42] and is dependent on the Langmuir constant, $K_{L}\left(\mathrm{~L} \mathrm{mg}^{-1}\right)$, which shows the affinity between the heavy metal ions and the PANmod surface. In the Freundlich model, the favorability of the adsorption system is shown by the dimensionless $n$ in the range 2-10 [43], while the model constant is expressed as $K_{F}\left(\left(\mathrm{mg} \mathrm{g}^{-1}\right)\left(\mathrm{L} \mathrm{mg}^{-1}\right)^{1 / \mathrm{n}}\right)$. The mean free energy of adsorption $E$ $\left(\mathrm{kJ} \mathrm{mol}^{-1}\right.$, Table 3) in the D-R model is relevant to the model constant $K_{D R}\left(\mathrm{~mol} \mathrm{~kJ}^{-1}\right)^{2}$ and is used to describe whether the adsorption system is physical $\left(E<8 \mathrm{~kJ} \mathrm{~mol}^{-1}\right)$ or chemical $\left(E>8 \mathrm{~kJ} \mathrm{~mol}^{-1}\right) . T$ (Kelvin) and $R\left(8.314 \mathrm{~J} \mathrm{~mol}^{-1} \cdot \mathrm{K}^{-1}\right)$ are used in the $\mathrm{D}-\mathrm{R}$ and Temkin models and represent the absolute temperature and universal gas constant, respectively. The terms $n_{H}$ and $k_{H}$ are the exponent and constant in the Halsey isotherm, respectively, while both $A_{H J}$ and $B_{H J}$ are constants evaluated in the Harkins-Jura (H-J) model. The heat of adsorption and the binding constant at equilibrium in the Temkin model are expressed by $H_{\text {ads }}\left(\mathrm{kJ} \mathrm{mol}^{-1}\right)$ and $K_{T}\left(\mathrm{~L} \mathrm{mg}^{-1}\right)$, respectively (Table 3$)$.

The constant of the Sips model, $K_{S}\left(\mathrm{~L} \mathrm{~g}^{-1}\right)$, is related to the energy of adsorption, while the degree of heterogeneity is expressed by the dimensionless number $\left(n_{S}\right)$ in Equation (7). Both $\alpha\left(\mathrm{L} \mathrm{mg}^{-1}\right)$ and dimensionless $\beta(0-1)$ are parameters used in $\mathrm{R}-\mathrm{P}$ isotherm with the model's constant being expressed by $K_{R P}\left(\mathrm{~L} \mathrm{~g}^{-1}\right)$ in Equation (8). Table 4 lists the values of the parameters mentioned above for all the isotherm models evaluated, by using the slope and intercept values in the respective linearized plots; OriginPro 8.5 and CurveExpert Professional software were used for the nonlinear approach. The suitability of the nonlinear two-parameter and three-parameter isotherms to the experimental data of both heavy metal ions is shown in Figure 6 for an equilibrium contact time of $60 \mathrm{~min}$, as described earlier. We analyzed the adsorption data for batch tests performed at $30^{\circ} \mathrm{C}$ by using $0.5 \mathrm{~g}$ of PANmod; the solution $\mathrm{pH}$ was maintained at $5 \pm 0.2$ and $7 \pm 0.2$ for $\mathrm{Pb}^{2+}$ and $\mathrm{Ni}^{2+}$, respectively.

As shown in Figure 6a, the Langmuir model poorly fitted the $\mathrm{Ni}^{2+}$ adsorption; the same result was obtained by applying the Freundlich model to $\mathrm{Pb}^{2+}$ adsorption data (Figure $6 \mathrm{~b}$ ). This is reflected by low $R^{2}$ for both nonlinear and linearized fittings of the $\mathrm{Ni}^{2+}$ and $\mathrm{Pb}^{2+}$ adsorption in the Langmuir and Freundlich isotherm models, respectively (Table 4). The theoretical adsorption capacities were in good agreement with the experimental values for both the Langmuir and Freundlich isotherm models for $\mathrm{Pb}^{2+}$, but a $\sim 10 \%$ disagreement between the experimental and calculated values was observed for $\mathrm{Ni}^{2+}$ in both models. The values of the separation factor in the Langmuir model, $0<R_{L}<1$, and the dimensionless factor $n$ of 2-10 in the Freundlich model indicated that both isotherms fit well the adsorption of $\mathrm{Pb}^{2+}$ and $\mathrm{Ni}^{2+}$ by both the nonlinear as well as the linearized 
approach (Table 4). Considerably higher values of the model constants for both Langmuir and Freundlich isotherms were obtained for $\mathrm{Ni}^{2+}$, in comparison to $\mathrm{Pb}^{2+}$; the $K_{L}$ values of 2.66 and $11.89 \mathrm{~L} \mathrm{mg}^{-1}$ (Table 4) show the better affinity between the PANmod surface and $\mathrm{Ni}^{2+}$, compared with $\mathrm{Pb}^{2+}$, respectively. On the other hand, high $R^{2}$ values and close agreement of the theoretical adsorption capacities with the experimental values for the Langmuir model suggest a monolayer adsorption of $\mathrm{Pb}^{2+}$ on the PANmod surface.

Table 4. Estimated parameter values in the nonlinear and linearized isotherm models for $\mathrm{Pb}^{2+}$ and $\mathrm{Ni}^{2+}$ (contact time $=60 \mathrm{~min}$, PANmod dose $=0.5 \mathrm{~g}, \mathrm{pH}=5 \pm 0.2$ and $7 \pm 0.2$ for $\mathrm{Pb}^{2+}$ and $\mathrm{Ni}^{2+}$, respectively).

\begin{tabular}{|c|c|c|c|c|c|}
\hline \multirow{2}{*}{ Isotherm } & \multirow{2}{*}{ Parameter } & \multicolumn{2}{|c|}{$\mathrm{Pb}^{2+}$} & \multicolumn{2}{|c|}{$\mathrm{Ni}^{2+}$} \\
\hline & & Nonlinear & Linear & Nonlinear & Linear \\
\hline & $q_{\mathrm{e} \exp }, \mathrm{mg} \mathrm{g}^{-1}$ & \multicolumn{2}{|c|}{$\begin{array}{l}13.05 \text { (against } 30 \mathrm{mg} \\
\mathrm{L}^{-1} \text { ) }\end{array}$} & \multicolumn{2}{|c|}{56 (against $50 \mathrm{mg} \mathrm{L}^{-1}$ ) } \\
\hline \multirow{4}{*}{ Langmuir } & $q_{m}, \mathrm{mg} \mathrm{g}^{-1}$ & 13.67 & 14.12 & 49.38 & 44.25 \\
\hline & $K_{L}, \mathrm{~L} \mathrm{mg}^{-1}$ & 0.56 & 0.44 & 2.66 & 11.89 \\
\hline & $R_{L}$ & 0.056 & 0.07 & 0.0075 & 0.002 \\
\hline & $R^{2}$ & 0.91 & 0.96 & 0.62 & 0.78 \\
\hline \multirow{4}{*}{ Freundlich } & $q_{m}, \mathrm{mg} \mathrm{g}^{-1}$ & 12.90 & 13.75 & 63.44 & 64.22 \\
\hline & $K_{F},\left(\left(\mathrm{mg} \mathrm{g}^{-1}\right)\left(\mathrm{L} \mathrm{mg}^{-1}\right)^{1 / \mathrm{n}}\right)$ & 7.74 & 7.20 & 31.37 & 33.44 \\
\hline & $n$ & 6.67 & 5.26 & 5.56 & 6.00 \\
\hline & $R^{2}$ & 0.64 & 0.72 & 0.97 & 0.97 \\
\hline \multirow{4}{*}{$\mathrm{D}-\mathrm{R}$} & $q_{m}, \mathrm{mg} \mathrm{g}^{-1}$ & 12.74 & 12.7 & 48.55 & 44.54 \\
\hline & $K_{D R},\left(\mathrm{~mol} \mathrm{~kJ}^{-1}\right)^{2}$ & $66 \times 10^{-8}$ & $60 \times 10^{-8}$ & $15 \times 10^{-8}$ & $2 \times 10^{-8}$ \\
\hline & $E, \mathrm{~kJ} \mathrm{~mol}^{-1}$ & 0.87 & 0.91 & 1.8 & 5.0 \\
\hline & $R^{2}$ & 0.96 & 0.98 & 0.31 & 0.66 \\
\hline \multirow{4}{*}{ Halsey } & $q_{\mathrm{e} \mathrm{cal}}, \mathrm{mg} \mathrm{g}^{-1}$ & 12.3 & 11.02 & 54.15 & 62.3 \\
\hline & $n_{H}$ & -6.7 & -5.26 & -5.7 & -6.00 \\
\hline & $K_{H}$ & 0.000 & 0.65 & 0.000 & 0.177 \\
\hline & $R^{2}$ & 0.64 & 0.72 & 0.97 & 0.97 \\
\hline \multirow{3}{*}{ Temkin } & $K_{T}, \mathrm{~L} \mathrm{mg}^{-1}$ & 45.20 & 45.09 & 278.57 & 278.58 \\
\hline & $H_{a d s}, \mathrm{~kJ} \mathrm{~mol}^{-1}$ & 0.56 & 1.4 & 0.17 & 0.4 \\
\hline & $R^{2}$ & 0.71 & 0.74 & 0.92 & 0.97 \\
\hline \multirow{3}{*}{$\mathrm{H}-\mathrm{J}$} & $A_{H J}, \mathrm{mg} \mathrm{g}^{-1}$ & 76.9 & 89.29 & 175 & 1428.6 \\
\hline & $B_{H J}$ & 4.5 & 1.96 & 2.9 & 1.71 \\
\hline & $R^{2}$ & 0.63 & 0.65 & 1.00 & 0.95 \\
\hline \multirow{4}{*}{ Sips } & $q_{m}, \mathrm{mg} \mathrm{g}^{-1}$ & 12.87 & & 64.81 & \\
\hline & $K_{S}, \mathrm{~L} \mathrm{~g}^{-1}$ & 0.29 & & 0.5 & \\
\hline & $n_{S}$ & 0.76 & & 0.18 & \\
\hline & $R^{2}$ & 0.97 & & 0.99 & \\
\hline \multirow{4}{*}{$\mathrm{R}-\mathrm{P}$} & $K_{R P}, \mathrm{~L} \mathrm{~g}^{-1}$ & 4.73 & & 7.1 & \\
\hline & $\alpha, \mathrm{L} \mathrm{mg}^{-1}$ & 0.2 & & 2.25 & \\
\hline & $\beta$ & 0.15 & & 0.82 & \\
\hline & $R^{2}$ & 0.97 & & 0.99 & \\
\hline
\end{tabular}

Figure $6 \mathrm{c}$ shows that the D- $\mathrm{R}$ isotherm fitted the $\mathrm{Ni}^{2+}$ adsorption data poorly, which is further reflected by the very low $R^{2}$ value 0.31 (Table 4); however, the model described well the $\mathrm{Pb}^{2+}$ adsorption data with both the linear and nonlinear approaches; the calculated adsorption capacities are in close agreement with those of the experimental values. The estimated values of the mean free energy of adsorption, $E<8 \mathrm{~kJ} \mathrm{~mol}^{-1}$ clearly reflect a physical adsorption of both types of heavy metal ions on the PANmod surface (Table 4). Based on the observed $R^{2}$ values, the Temkin isotherm also represented better the adsorption data of $\mathrm{Ni}^{2+}$ compared to $\mathrm{Pb}^{2+}$, as shown in Table 4. This reflects the heterogeneous 
adsorption [44] of $\mathrm{Ni}^{2+}$ with uniform distribution of binding energies on the surface of the PANmod. The same is also proposed based on the suitability of the Freundlich isotherm for representing the adsorption data of $\mathrm{Ni}^{2+}$.
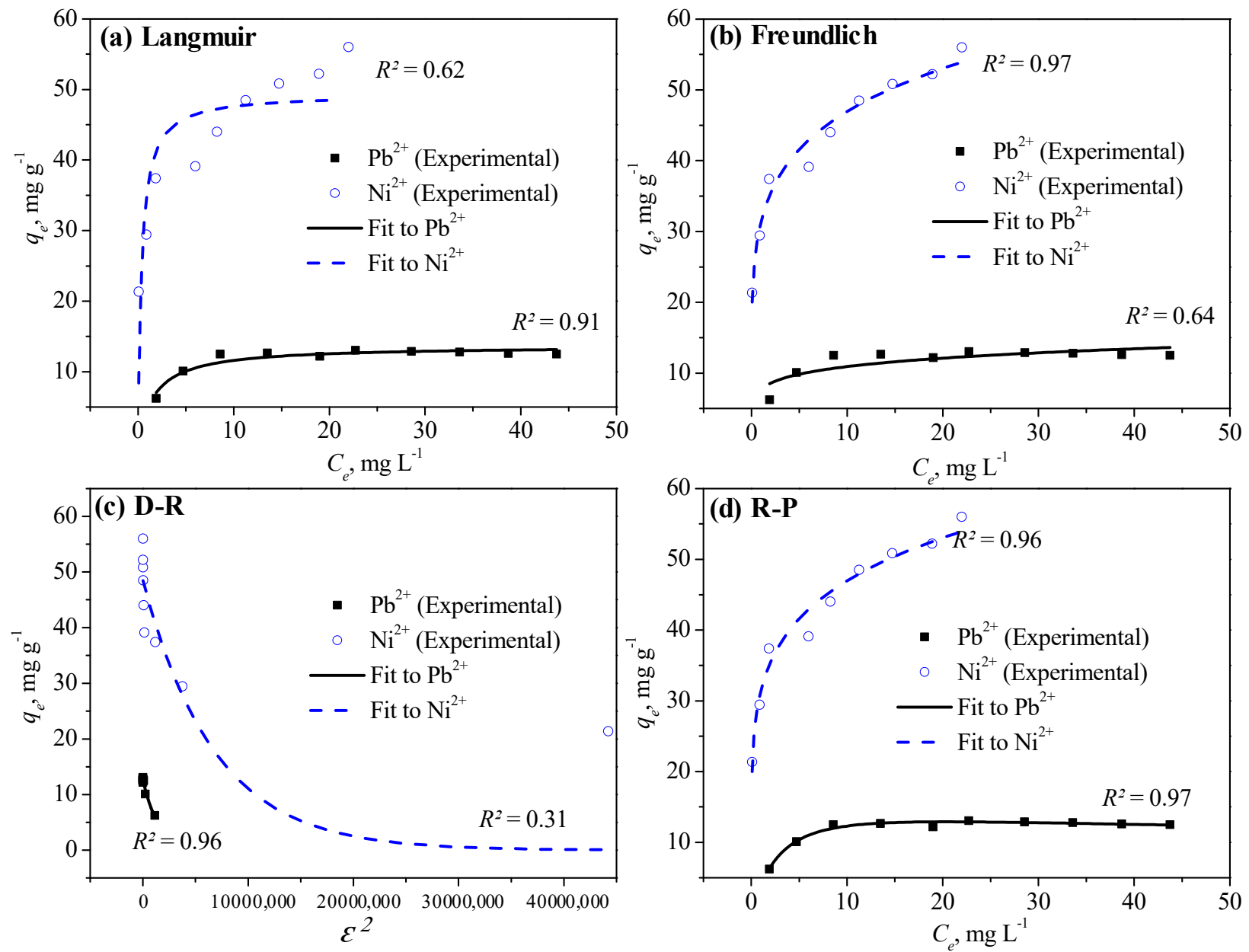

Figure 6. Nonlinear and linearized fitting of (a) Langmuir, (b) Freundlich, (c) Dubinin-Radushkevich (D-R), and (d) RedlichPeterson (R-P) to the adsorption data of $\mathrm{Pb}^{2+}$ and $\mathrm{Ni}^{2+}$ onto PANmod.

As in the case of the Temkin isotherm, both the Halsey and H-J models proved to fit better the adsorption data for $\mathrm{Ni}^{2+}$ compared to $\mathrm{Pb}^{2+}$, as reflected by the high $R^{2}$ values shown in Table 4. Based on the results of the Temkin model, the adsorption of $\mathrm{Ni}^{2+}$ on the PANmod occurred with a lower heat of adsorption $\left(0.17 \mathrm{~kJ} \mathrm{~mol}^{-1}\right)$ but a much higher equilibrium binding constant $\left(288 \mathrm{~L} \mathrm{mg}^{-1}\right.$ ) compared to $\mathrm{Pb}^{2+}$ (Table 4$)$. The suitability of both the Halsey and $\mathrm{H}-\mathrm{J}$ models in describing the adsorption process relates the multilayer adsorption of $\mathrm{Ni}^{2+}$ on PANmod with its heteroporous nature, suggesting a heterogeneous pore distribution. Figure $6 \mathrm{~d}$ illustrates the R-P model excellent fit of the adsorption data of both heavy metal ions; the high values of the $R^{2}$ in Table 4 confirm the same for the other three-parameter isotherms that were used, that is the Sips model, proposing both homogeneous and heterogeneous adsorption of the $\mathrm{Ni}^{2+}$ and $\mathrm{Pb}^{2+}$ ions on PANmod [45-48]. In describing the adsorption of $\mathrm{Ni}^{2+}$, the Sips model slightly overestimated the theoretical adsorption capacity compared to the experimental value; a lower energy of adsorption and lesser degree of heterogeneity was evaluated for $\mathrm{Ni}^{2+}$ in comparison to the adsorption of $\mathrm{Pb}^{2+}$. 


\section{Conclusions}

Here, we studied the successful adsorption of the heavy metal ions $\mathrm{Pb}^{2+}$ and $\mathrm{Ni}^{2+}$ on an electrospun membrane of PAN nanofiber activated with $\mathrm{NaHCO}_{3}$ (PANmod). The FTIR analysis revealed the polar interactions between PAN nanofibers and $\mathrm{NaHCO}_{3}$, helping the successful adsorption of $\mathrm{Ni}^{2+}$ and $\mathrm{Pb}^{2+}$ on the PANmod surface. Furthermore, the FE-SEM images and the elemental analysis using EDX revealed the functionalization of the PAN nanofiber with $\mathrm{NaHCO}_{3}$, and the agglomeration of $\mathrm{Pb}^{2}$ and $\mathrm{Ni}^{2+}$ on PANmod.

After rapid uptake of the heavy metal ions by the PANmod during immediate contact (15 min), a linear increase in both the adsorption capacity and removal efficiency was observed; equilibrium was attained $60 \mathrm{~min}$ after the contact started. Among the conventional kinetic models, the PSO kinetic model describes best the adsorption of both ion types on the PANmod sample; the calculated $R^{2}$ values (0.9-0.99) closely agreed with the estimated adsorption capacities, and also with the experimental values.

The percentage removal, after increasing for both heavy metal ions from 2 to 7 , decreased from $73 \%$ to $21 \%$ and from $91 \%$ to $73 \%$ for $\mathrm{Pb}^{2+}$ and $\mathrm{Ni}^{2+}$, respectively, as the solution $\mathrm{pH}$ increased further from 7.0 to 9.0. The uptake of $\mathrm{Pb}^{2+}$ and $\mathrm{Ni}^{2+}$ by the PANmod increased linearly as the initial concentration of metal ions increased from 5.0 to $20 \mathrm{mg} \mathrm{L}^{-1}$; at the maximum value of the initial ion concentration $\left(50 \mathrm{mg} \mathrm{L}^{-1}\right)$, the maximum adsorption capacities corresponding to the $\mathrm{Pb}^{2+}$ and $\mathrm{Ni}^{2+}$ ions were 13 and $56 \mathrm{mg} \mathrm{g}^{-1}$, respectively. The optimal dose of PANmod, corresponding to a maximum uptake of $\mathrm{Pb}^{2+}$ and $\mathrm{Ni}^{2+}$, was found to be 0.7 and $0.2 \mathrm{~g}$, respectively; the adsorption capacity decreased with further increase in the adsorbent dose.

Among the two-parameter isotherm models, the Langmuir model fitted better the $\mathrm{Pb}^{2+}$ adsorption data, suggesting a monolayer adsorption. The Freundlich model fitted the $\mathrm{Ni}^{2+}$ adsorption on the surface of the PANmod better than that of $\mathrm{Pb}^{2+}$, reflecting a heterogeneous adsorption of $\mathrm{Ni}^{2+}$ with a uniform distribution of binding energies on the surface of the PANmod. The estimated values of the mean free energy of adsorption for the D-R isotherm, $E<8 \mathrm{~kJ} \mathrm{~mol}^{-1}$, reflected clearly a physical adsorption of both the heavy metal ions on the surface of the PANmod. As in the case of the Temkin isotherm, both the Halsey and $\mathrm{H}-\mathrm{J}$ models proved to be better fits of the adsorption data for $\mathrm{Ni}^{2+}$ than that of to $\mathrm{Pb}^{2+}$, revealing the multilayer adsorption of $\mathrm{Ni}^{2+}$ onto PANmod with heteroporous nature and suggesting heterogeneous pore distribution.

Author Contributions: Conceptualization, M.T.A. and A.A.A.; methodology, M.S.; software, M.T.A.; validation, M.T.A. and A.A.A.; formal analysis, M.S.; investigation, M.T.A. and M.S.; resources, A.A.A.; data curation, M.T.A.; writing—original draft preparation, M.T.A.; writing—review and editing, M.T.A. and A.A.A.; visualization, M.S.; supervision, A.A.A.; project administration, M.T.A. and M.S.; funding acquisition, A.A.A. All authors have read and agreed to the published version of the manuscript.

Funding: This project was funded by the National Plan for Science, Technology and Innovation (MAARIFAH), King Abdulaziz City for Science and Technology, Kingdom of Saudi Arabia, Award Number (12-WAT2623-02).

Data Availability Statement: Data is contained within the article.

Conflicts of Interest: The authors declare no conflict of interest. The funders had no role in the design of the study; in the collection, analyses, or interpretation of data; in the writing of the manuscript, or in the decision to publish the results.

\section{References}

1. Qin, H.; Su, Q.; Khu, S.-T.; Tang, N. Water Quality Changes during Rapid Urbanization in the Shenzhen River Catchment: An Integrated View of Socio-Economic and Infrastructure Development. Sustainability 2014, 6, 7433-7451. [CrossRef]

2. Islam, M.A.; Awual, M.R.; Angove, M.J. A review on nickel(II) adsorption in single and binary component systems and future path. J. Environ. Chem. Eng. 2019, 7, 103305. [CrossRef] 
3. Montazer-Rahmati, M.M.; Rabbani, P.; Abdolali, A.; Keshtkar, A.R. Kinetics and equilibrium studies on biosorption of cadmium, lead, and nickel ions from aqueous solutions by intact and chemically modified brown algae. J. Hazard. Mater. 2011, 185, 401-407. [CrossRef] [PubMed]

4. Amin, M.T.; Alazba, A.A.; Shafiq, M. Comparative Sorption of Nickel from an Aqueous Solution Using Biochar Derived from Banana and Orange Peel Using a Batch System: Kinetic and Isotherm Models. Arab. J. Sci. Eng. 2019, 44, 10105-10116. [CrossRef]

5. Bartczak, P.; Norman, M.; Klapiszewski, Ł.; Karwańska, N.; Kawalec, M.; Baczyńska, M.; Wysokowski, M.; Zdarta, J.; Ciesielczyk, F.; Jesionowski, T. Removal of nickel(II) and lead(II) ions from aqueous solution using peat as a low-cost adsorbent: A kinetic and equilibrium study. Arab. J. Chem. 2018, 11, 1209-1222. [CrossRef]

6. Algureiri, A.H.; Abdulmajeed, Y.R. Removal of Heavy Metals from Industrial Wastewater by Using RO Membrane. Iraqi J. Chem. Pet. Eng. 2016, 17, 125-136.

7. Zewail, T.M.; Yousef, N.S. Kinetic study of heavy metal ions removal by ion exchange in batch conical air spouted bed. Alex. Eng. J. 2015, 54, 83-90. [CrossRef]

8. Brbooti, M.M.; Abid, B.A.; Al-Shuwaiki, N.M. Removal of Heavy Metals Using Chemicals Precipitation. Eng. Technol. J. 2011, 29, 595-612.

9. Mohammadi, T.; Moheb, A.; Sadrzadeh, M.; Razmi, A. Modeling of metal ion removal from wastewater by electrodialysis. Sep. Purif. Technol. 2005, 41, 73-82. [CrossRef]

10. Tang, X.; Zheng, H.; Teng, H.; Sun, Y.; Guo, J.; Xie, W.; Yang, Q.; Chen, W. Chemical coagulation process for the removal of heavy metals from water: A review. Desalin. Water Treat. 2016, 57, 1733-1748. [CrossRef]

11. Rajasulochana, P.; Preethy, V. Comparison on efficiency of various techniques in treatment of waste and sewage water-A comprehensive review. Resour. Effic. Technol. 2016, 2, 175-184. [CrossRef]

12. Barakat, M.A. New trends in removing heavy metals from industrial wastewater. Arab. J. Chem. 2011, 4, 361-377. [CrossRef]

13. De Gisi, S.; Lofrano, G.; Grassi, M.; Notarnicola, M. Characteristics and adsorption capacities of low-cost sorbents for wastewater treatment: A review. Sustain. Mater. Technol. 2016, 9, 10-40. [CrossRef]

14. Shafiq, M.; Alazba, A.A.; Amin, M.T. Lead and copper scavenging from aqueous solutions using Eucalyptus camaldulensis derived activated carbon: Equilibrium, kinetics and sorption mechanism. DWT 2019, 158, 187-198. [CrossRef]

15. Deng, F.; Luo, X.-B.; Ding, L.; Luo, S.-L. Application of Nanomaterials and Nanotechnology in the Reutilization of Metal Ion From Wastewater. In Nanomaterials for the Removal of Pollutants and Resource Reutilization; Luo, X., Deng, F., Eds.; Micro and Nano Technologies; Elsevier: Amsterdam, The Netherlands, 2019; pp. 149-178, ISBN 978-0-12-814837-2.

16. Pandey, N.; Shukla, S.K.; Singh, N.B. Water purification by polymer nanocomposites: An overview. Nanocomposites 2017, 3, 47-66. [CrossRef]

17. Amin, M.T.; Alazba, A.A.; Manzoor, U. A Review of Removal of Pollutants from Water/Wastewater Using Different Types of Nanomaterials. Available online: https:/ / www.hindawi.com/journals/amse/2014/825910/ (accessed on 16 December 2020).

18. Jiang, J.; Srinivas, K.; Kiziltas, A.; Geda, A.; Ahring, B.K. Rheology of Polyacrylonitrile/Lignin Blends in Ionic Liquids under Melt Spinning Conditions. Molecules 2019, 24, 2650. [CrossRef] [PubMed]

19. Chaúque, E.F.C.; Dlamini, L.N.; Adelodun, A.A.; Greyling, C.J.; Catherine Ngila, J. Modification of electrospun polyacrylonitrile nanofibers with EDTA for the removal of Cd and Cr ions from water effluents. Appl. Surf. Sci. 2016, 369, 19-28. [CrossRef]

20. Chen, I.-H.; Wang, C.-C.; Chen, C.-Y. Fabrication and Structural Characterization of Polyacrylonitrile and Carbon Nanofibers Containing Plasma-Modified Carbon Nanotubes by Electrospinning. J. Phys. Chem. C 2010, 114, 13532-13539. [CrossRef]

21. Aijaz, M.O.; Karim, M.R.; Alharbi, H.F.; Alharthi, N.H. Novel optimised highly aligned electrospun PEI-PAN nanofibre mats with excellent wettability. Polymer 2019, 180, 121665. [CrossRef]

22. Anjum, M.; Miandad, R.; Waqas, M.; Gehany, F.; Barakat, M.A. Remediation of wastewater using various nano-materials. Arab. J. Chem. 2019, 12, 4897-4919. [CrossRef]

23. Wang, C.; Wang, J.; Zeng, L.; Qiao, Z.; Liu, X.; Liu, H.; Zhang, J.; Ding, J. Fabrication of Electrospun Polymer Nanofibers with Diverse Morphologies. Molecules 2019, 24, 834. [CrossRef] [PubMed]

24. Choi, J.-Y.; Kim, D.-S. Adsorption behavior of zinc and cadmium ion on granular activated carbon in singular and binary systems and the influence of nitrilotricetic acid as a complexing agent. J. Environ. Sci. Health A Tox Hazard Subst Environ. Eng. 2002, 37, 1701-1719. [CrossRef] [PubMed]

25. Patel, S.; Hota, G. Adsorptive removal of malachite green dye by functionalized electrospun PAN nanofibers membrane. Fibers Polym. 2014, 15, 2272-2282. [CrossRef]

26. Arjmandi, R.; Hassan, A.; Eichhorn, S.J.; Mohamad Haafiz, M.K.; Zakaria, Z.; Tanjung, F.A. Enhanced ductility and tensile properties of hybrid montmorillonite/cellulose nanowhiskers reinforced polylactic acid nanocomposites. J. Mater. Sci. 2015, 50, 3118-3130. [CrossRef]

27. Ouyang, Q.; Cheng, L.; Wang, H.; Li, K. Mechanism and kinetics of the stabilization reactions of itaconic acid-modified polyacrylonitrile. Polym. Degrad. Stab. 2008, 93, 1415-1421. [CrossRef]

28. Arshad, S.N.; Naraghi, M.; Chasiotis, I. Strong carbon nanofibers from electrospun polyacrylonitrile. Carbon 2011, 49, 1710-1719. [CrossRef]

29. Hildebrando, E.A.; Andrade, C.G.B.; da Rocha Junior, C.A.F.; Angélica, R.S.; Valenzuela-Diaz, F.R.; Neves, R.D.F. Synthesis and characterization of zeolite NaP using kaolin waste as a source of silicon and aluminum. Mat. Res. 2014, 17, 174-179. [CrossRef] 
30. Huo, Z.; Xu, X.; Lv, Z.; Song, J.; He, M.; Li, Z.; Wang, Q.; Yan, L.; Li, Y. Thermal study of NaP zeolite with different morphologies. J. Therm. Anal. Calorim. 2013, 111, 365-369. [CrossRef]

31. Tang, H.; Zhou, W.; Zhang, L. Adsorption isotherms and kinetics studies of malachite green on chitin hydrogels. J. Hazard. Mater. 2012, 209-210, 218-225. [CrossRef]

32. Chowdhury, S.; Mishra, R.; Saha, P.; Kushwaha, P. Adsorption thermodynamics, kinetics and isosteric heat of adsorption of malachite green onto chemically modified rice husk. Desalination 2011, 265, 159-168. [CrossRef]

33. Taty-Costodes, V.C.; Fauduet, H.; Porte, C.; Delacroix, A. Removal of Cd(II) and Pb(II) ions, from aqueous solutions, by adsorption onto sawdust of Pinus sylvestris. J. Hazard. Mater. 2003, 105, 121-142. [CrossRef] [PubMed]

34. Karapinar, N.; Donat, R. Adsorption behaviour of $\mathrm{Cu}^{2+}$ and $\mathrm{Cd}^{2+}$ onto natural bentonite. Desalination 2009, $249,123-129$. [CrossRef]

35. Raji, F.; Pakizeh, M. Study of $\mathrm{Hg}(\mathrm{II})$ species removal from aqueous solution using hybrid ZnCl2-MCM-41 adsorbent. Appl. Surf. Sci. 2013, 282, 415-424. [CrossRef]

36. Karthik, R.; Meenakshi, S. Removal of $\mathrm{Pb}(\mathrm{II})$ and $\mathrm{Cd}(\mathrm{II})$ ions from aqueous solution using polyaniline grafted chitosan. Chem. Eng. J. 2015, 263, 168-177. [CrossRef]

37. Kampalanonwat, P.; Supaphol, P. Preparation and Adsorption Behavior of Aminated Electrospun Polyacrylonitrile Nanofiber Mats for Heavy Metal Ion Removal. ACS Appl. Mater. Interfaces 2010, 2, 3619-3627. [CrossRef]

38. Dastbaz, A.; Keshtkar, A.R. Adsorption of $\mathrm{Th}^{4+}, \mathrm{U}^{6+}, \mathrm{Cd}^{2+}$, and $\mathrm{Ni}^{2+}$ from aqueous solution by a novel modified polyacrylonitrile composite nanofiber adsorbent prepared by electrospinning. Appl. Surf. Sci. 2014, 293, 336-344. [CrossRef]

39. Abdullah, N.; Tajuddin, M.H.; Yusof, N.; Jaafar, J.; Aziz, F.; Misdan, N. Removal of Lead(II) from Aqueous Solution Using Polyacrylonitrile/Zinc Oxide Activated Carbon Nanofibers. MJAS 2017, 21. [CrossRef]

40. Mokhtari, M.; Keshtkar, A.R. Removal of Th(IV), Ni(II)and Fe(II) from aqueous solutions by a novel PAN-TiO2 nanofiber adsorbent modified with aminopropyltriethoxysilane. Res. Chem. Intermed. 2016, 42, 4055-4076. [CrossRef]

41. Zhao, R.; Li, X.; Sun, B.; Shen, M.; Tan, X.; Ding, Y.; Jiang, Z.; Wang, C. Preparation of phosphorylated polyacrylonitrile-based nanofiber mat and its application for heavy metal ion removal. Chem. Eng. J. 2015, 268, 290-299. [CrossRef]

42. Foo, K.Y.; Hameed, B.H. Preparation, characterization and evaluation of adsorptive properties of orange peel based activated carbon via microwave induced $\mathrm{K}_{2} \mathrm{CO}_{3}$ activation. Bioresour. Technol. 2012, 104, 679-686. [CrossRef]

43. Malik, P.K. Use of activated carbons prepared from sawdust and rice-husk for adsorption of acid dyes: A case study of Acid Yellow 36. Dye. Pigment. 2003, 56, 239-249. [CrossRef]

44. Kumar, P.S.; Ramakrishnan, K.; Gayathri, R. Removal of Nickel(II) from Aqueous Solutions by Ceralite IR 120 Cationic Exchange Resins. J. Eng. Sci. Technol. 2010, 5, 232-243.

45. Gimbert, F.; Morin-Crini, N.; Renault, F.; Badot, P.-M.; Crini, G. Adsorption isotherm models for dye removal by cationized starch-based material in a single component system: Error analysis. J. Hazard. Mater. 2008, 157, 34-46. [CrossRef] [PubMed]

46. Abtahi, M.; Mesdaghinia, A.; Saeedi, R.; Nazmara, S. Biosorption of As(III) and As(V) from aqueous solutions by brown macroalga Colpomenia sinuosa biomass: Kinetic and equilibrium studies. Desalin. Water Treat. 2013, 51, 3224-3232. [CrossRef]

47. Naddafi, K.; Rastkari, N.; Nabizadeh, R.; Saeedi, R.; Gholami, M.; Sarkhosh, M. Adsorption of 2,4,6-trichlorophenol from aqueous solutions by a surfactant-modified zeolitic tuff: Batch and continuous studies. Desalin. Water Treat. 2016, 57, 5789-5799. [CrossRef]

48. Günay, A.; Arslankaya, E.; Tosun, İ. Lead removal from aqueous solution by natural and pretreated clinoptilolite: Adsorption equilibrium and kinetics. J. Hazard. Mater. 2007, 146, 362-371. [CrossRef] 